\title{
AUTORIDAD E INSPIRACIÓN EN ÉPOCA IMPERIAL: ANÁLISIS DE ALGUNOS PASAJES PARALELOS EN ATENEO Y ELIANO*
}

\author{
Lucía Rodríguez-Noriega Guillén \\ Universidad de Oviedo \\ lnoriega@uniovi.es
}

\section{RESUMEN}

El Banquete de los eruditos de Ateneo es la fuente directa (nunca reconocida) de algunos pasajes de Eliano, sobre todo en las Historias curiosas, pero también en la Historia de los animales. El objetivo de este artículo es la comparación de algunos de esos pasajes, con el fin de arrojar luz sobre el manejo que ambos hacen de sus fuentes y de cómo las citan, así como sobre sus respectivas personalidades como autores literarios.

Palabras Clave: Claudio Eliano, Ateneo de Náucratis, intertextualidad, autores griegos de época imperial.

AUTHORITY AND INSPIRATION IN AUTHORS OF THE EMPIRE:

ANALYSIS OF SOME PARALLEL PASSAGES IN ATHENAEUS AND AELIAN

\section{ABSTRACT}

Athenaeus' Deipnosophistae is the (never explicitly admitted) direct source of some of Aelian's passages, especially in the Varia Historia, but also in the Natura Animalium. The aim of this article is the comparison of some of these passages, in order to cast some light on the way both use and quote their sources, and on their personality as writers.

KeYwords: Claudius Aelian, Athenaeus of Naucratis, intertextuality, Greco-Roman scholars of the Empire.

\section{INTRODUCCIÓN. AUTORIDAD E INSPIRACIÓN EN ATENEO Y ELIANO}

Como en la generalidad de los autores griegos de los siglos II y III d.C., en Ateneo de Náucratis y en Claudio Eliano se observa una relación compleja entre erudición y originalidad, con una continua reutilización en su producción literaria de material recogido al hilo de las más variadas lecturas. Para estos autores y sus contemporáneos, lectura y escritura eran dos actividades estrechamente vinculadas, de manera que, al mismo tiempo que leían, iban seleccionando y resumiendo aquello 
que llamaba su atención, y coleccionándolo en forma de notas y fichas, con el fin de emplearlo después en sus propios escritos. Ahora bien, el hecho innegable de que su proceso creativo comenzase con este tipo de búsquedas a través de otros textos no significa que sus obras sean simples contenedores de citas, carentes de originalidad o interés literario, ni que su tratamiento de ese material fuera, ni mucho menos, igual.

Ateneo, nacido en la antigua colonia griega de Náucratis, en Egipto, se formó como gramático en Alejandría, cuya famosa biblioteca frecuentó con provecho en su juventud ${ }^{1}$. Emigrado más adelante a Roma, también en la capital del Imperio tuvo acceso a gran cantidad de libros, gracias sobre todo a la nutrida biblioteca del rico Publio Larensio ${ }^{2}$, cuyo correlato literario es el anfitrión del festín narrado en El banquete de los eruditos. La obra, en la que es patente el interés gramatical, erudito y de anticuario, está escrita para un grupo selecto de lectores cultos, a los que Ateneo pretendía dotar de una especie de «Enciclopedia del banquete». Así, para cada tema hizo acopio de una información tan exhaustiva como le fue posible, que presenta en su obra de una manera acumulativa, hasta agotar cada punto tratado. Pero, en lugar de darle a su escrito la, sin duda, práctica, pero poco interesante forma de léxico, lo que escribió fue un banquete, un diálogo narrado al estilo platónico. Los datos eruditos se traen a colación conforme avanza el relato de lo que ocurre en el banquete, normalmente a través del diálogo en estilo directo entre los invitados, pero a veces también de un modo más convencional, cuando el narrador, identificado con el autor, resume lo fundamental de sus conversaciones ${ }^{3}$.

Por lo que se refiere a Eliano, la selección de temas para sus obras y la manera en que los elabora y presenta al lector están condicionadas por tres factores fundamentales: la influencia de las prácticas retóricas al uso, sus ideas ético-filosóficas, y el deseo de combinar lo didáctico con el entretenimiento. Así, tanto para la Historia de los animales $(H A)$ como para las Historias curiosas $(V A)$ eligió el mismo formato, una colección de historietas cortas totalmente independientes entre sí, a modo de relato misceláneo ${ }^{4}$. Desde el punto de vista literario, una de las características más

* Este artículo, que dedicamos afectuosamente al Profesor Ángel Martínez Fernández, ha sido elaborado en el seno del proyecto DISIECTA MEMBRA (FFI2017-83315-C2-1-P), financiado por el MINECO.

${ }^{1}$ Más datos sobre la biografía de Ateneo pueden verse en Rodríguez-Noriega, 1998: 7-13.

${ }^{2}$ Tanto es así que el Banquete de los eruditos ha sido descrito como «[the] literary and artistic embodiment» de la biblioteca de Larensio (Jacob, 2000: 87). Sobre Larensio y su biblioteca, véase así mismo Braund, 2000.

${ }^{3}$ Sobre la estructura y la organización de la obra pueden verse Rodríguez-Noriega, 2000, y Jacob, 2013, ambos con bibliografía.

${ }^{4}$ Sus Cartas rústicas, aunque pertenecientes a un género diferente, responden en el fondo a un patrón similar. Aparte de estas obras, nos han llegado algunos fragmentos de un tratado suyo Sobre la providencia y otro Sobre las manifestaciones divinas, que parecen haber constado de una serie de historias morales sobre los castigos impuestos por los dioses a los incrédulos. También se atribuyen a Eliano dos epigramas (Epigr. Gr. 1084, 1085). 
destacables de la producción de Eliano es precisamente esa renuncia a cualquier plan sistemático, además de su gusto por unir erudición con diversidad, variedad y originalidad. Él mismo dice en el «Epílogo» de la $H A$, defendiéndose de posibles críticos, que su intención es atraer a los lectores, evitándoles el aburrimiento que les produciría una organización monótona del material, lo que lo ha llevado a evitar secciones temáticas coherentes. Se trata de un formato de fácil lectura, que permite dejar y retomar la obra en cualquier momento, y apunta a un público mucho más amplio que el selecto grupo de eruditos para los que escribe Ateneo.

Las noticias biográficas que nos han llegado sobre Eliano y la propia lectura de sus obras ponen de manifiesto que había tenido una educación esmerada ${ }^{5}$. Ahora bien, es evidente que la suya no fue la típica formación romana, que incluía conocimientos de la lengua y literatura griegas, pero por detrás de las latinas. Pese a su tradicionalismo romano y, evidentemente, sin que ello fuera visto como una contradicción, Eliano tuvo una inmersión total en el sistema escolar griego. De este modo, logró adquirir unos conocimientos equiparables a los que podía tener cualquier autor procedente del oriente del Imperio, tanto en lo que se refiere a su familiaridad con los modelos literarios y retóricos griegos, como en cuanto a su dominio de la lengua hablada ${ }^{6}$ y escrita, de acuerdo con el modelo aticista propugnado por la Segunda Sofística ${ }^{7}$. Así, terminados sus estudios, Eliano eligió también el griego como vehículo, primero, de su actividad oratoria como sofista y, después, de su producción literaria ${ }^{8}$.

Como es sabido, en época imperial la formación escolar de los jóvenes que se educaban en griego seguía una serie de etapas, claramente pautadas, que partía de la escuela elemental del maestro de primeras letras y culminaba en la escuela superior

${ }^{5}$ Los datos que conocemos sobre la vida de Claudio Eliano proceden sobre todo de la Vida de los Sofistas de Filóstrato (624-625), así como de una breve entrada en la enciclopedia Suda ( $\alpha_{1} 178$ Adler). Sabemos, de este modo, que era originario de la ciudad de Preneste, en el Lacio; que presumía de no haber salido jamás de Italia; que sus conciudadanos lo apreciaban mucho como persona respetuosa de los usos romanos tradicionales; y que en algún momento ejerció de pontífice máximo. Aparte de esto, en el "Epílogo» de la $H A$ el propio Eliano alude a su renuncia a codearse con las altas esferas de la sociedad, afirmando que prefiere destacar por sus conocimientos y no por sus riquezas, al tiempo que defiende férreamente su independencia personal. Ese distanciamiento del poder, al que Eliano mira desde una cierta posición de superioridad moral, es un rasgo que se observa también en otros autores de la denominada «Segunda Sofística».

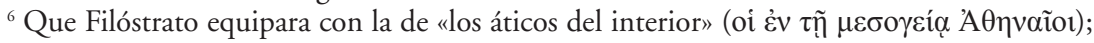
sobre el sentido exacto de la expresión de Filóstrato, que probablemente se refería a la pronunciación de Eliano en sus declamaciones orales, véase Vessella, 2018: 10-11.

${ }^{7}$ El estudio clásico de Schmid, 1893, sobre el aticismo de Eliano, debe ser corregido en algunos puntos, como se demuestra en Rodríguez-Noriega, 2005; sobre la lengua de Eliano véanse también Giangrande, 2011, y Rodríguez-Noriega 2005, 2007 y 2011.

${ }^{8}$ Esta renuncia a escribir en la lengua materna era una decisión que en la época resultaba totalmente natural en el caso de los sofistas no griegos del Oriente del Imperio, pero quizás no era tan de esperar de un hablante nativo del latín y residente en el Lacio. 
de retórica y oratoria?. La familiaridad con los grandes modelos literarios del pasado constituía, desde hacía siglos, una parte esencial de la $\pi \alpha 1 \delta \varepsilon^{\prime} \alpha$ griega. Era, sobre todo, en la etapa de formación intermedia cuando más hincapié se hacía en el estudio de la literatura, incluyendo la poesía, que en esta época se consideraba susceptible de inspirar a los prosistas sobre todo en cuestiones temáticas, aunque también se valoraba su capacidad de proporcionar a los estudiantes modelos de figuras de pensamiento y dicción, y de enriquecer su vocabulario. Ahora bien, lo que se propugnaba desde la práctica escolar no era en modo alguno una imitación literal de los modelos. Entre los ejercicios preparatorios que incluían los manuales de retórica al uso ${ }^{10}$ estaba la paráfrasis, que entrenaba a los futuros oradores y prosistas en la traducción a un estilo propio y contemporáneo (y, a ser posible, mejorándolo) del material tomado de obras precedentes, en verso o en prosa ${ }^{11}$.

Una vez concluido el período de educación intermedio, los estudiantes (salvo que decidieran estudiar derecho ${ }^{12}$ ) solían optar, como ya se ha apuntado, por seguir cursos superiores de filosofía o de retórica, éstos últimos orientados a proporcionar conocimientos especializados para la expresión en cualquier tipo de prosa. En el caso concreto de Eliano sabemos, gracias a Filóstrato (VS 625), que culminó sus estudios bajo el magisterio de Pausanias de Cesarea, quien ocupó la cátedra de Retórica en Roma entre los años 190 y 197 d.C, aunque, de nuevo según Filóstrato, el modelo que más admiraba era el de Herodes Ático.

Es indudable, por otra parte, que Eliano había recibido también formación filosófica y que llegó a desarrollar un pensamiento propio, fruto de una reflexión personal a partir de las enseñanzas adquiridas. En efecto, en su obra es patente una orientación filosófico-religiosa que, en consonancia con el eclecticismo típico de su época, se basa en parte en el pensamiento platónico y aristotélico, pero que, sobre todo, está vinculada al estoicismo contemporáneo (aunque algunas de sus ideas también están próximas a otras escuelas socráticas) ${ }^{13}$. Así, por ejemplo, el evidente interés de Eliano

9 Sobre la educación griega en la época helenística e imperial, véanse sobre todo Cribiore, $2005^{2}$, y Morgan, $2007^{3}$. Sigue siendo también de interés el clásico libro de Marrou, $1965^{6}$. Una sucinta visión panorámica del tema a lo largo de la historia de Grecia puede verse en Legras, 2004 ${ }^{3}$. Por lo que se refiere, en particular, a los autores de la Segunda Sofística, son de interés Whitmarsh, 2001: 90-13, e id., 2005. Sobre la educación en Roma hasta la muerte de Cómodo puede consultarse Wolff, 2015.

${ }^{10}$ Por ejemplo, por mencionar dos aproximadamente contemporáneos de Ateneo y Eliano, el de Teón (primera mitad del s. II d.C.) y el de Pseudo Hermógenes (s. III d.C.).

${ }^{11}$ Precisamente por eso, la práctica de la paráfrasis se observa con muchísima frecuencia en los autores de época imperial cuando citan a otros, algo que debemos tener muy presente, por ejemplo, si lo que nos interesa es reconstruir a través de sus citas un texto original perdido: salvo que se trate de citas poéticas que conserven su metro, o que el autor citante sea un gramático que busca el dato exacto, lo más probable es que el texto citado haya sido alterado y embellecido de un modo u otro por quien lo aduce, para acomodarlo a su nuevo contexto como parte integrante del mismo. Sobre la paráfrasis como ejercicio retórico véase, por ejemplo, Roberts, 1985: 5-54.

${ }^{12}$ Disciplina que, además, incluso en el oriente del Imperio se enseñaba en latín.

${ }^{13}$ Sobre el pensamiento de Eliano véanse García Valdés, 2003, e id., 2013. 
por los animales, que se plasma sobre todo en la $H A$, no es tanto científico como ético-filosófico ${ }^{14}$. Para Eliano, como para el estoicismo contemporáneo, los valores morales se rigen por la Ley Natural, que, a diferencia de las mutables leyes de los hombres, es firme, eterna y soberana.

El aspecto más interesante del pensamiento de Eliano puede explicarse en términos del cognitivismo moderno, siguiendo un conocido libro de Lakoff y Turner (1989: 160-213), mediante lo que estos autores llaman la "Gran Cadena del Ser» (The Great Chain of Being). La "Gran Cadena del Ser» es un modelo cultural que sigue vigente en nuestra cultura occidental moderna, y cuyo origen puede rastrearse hasta la Grecia antigua. Es, en buena parte, inconsciente, y tan fundamental para nuestro pensamiento que apenas nos percatamos de ella. Afecta a todos los tipos de entidades existentes, y los sitúa en una escala jerárquica básica (en sentido ascendente: Objetos naturales > Objetos complejos $>$ Plantas $>$ Animales $>$ Humanos). Además, en su versión extendida, la Gran Cadena tiene un nivel cósmico superior al humano, donde la concepción estoica de Eliano sitúa a Dios, identificado con la Naturaleza.

Pues bien, lo que resulta más interesante en el modo que tiene Eliano de entender la «Gran Cadena» es que, según él, mientras que los animales obedecen a la ley natural ciegamente, siguiendo su instinto, los hombres a menudo la incumplen porque usan su razón y su voluntad de un modo equivocado. En consecuencia, aunque los animales ocupan un nivel en la escala más bajo que los seres humanos, su comportamiento instintivo puede a menudo ofrecer un modelo para el hombre, según Eliano. Este principio determina la selección de muchos de los temas de la $H A$, gran parte de cuyos capítulos trata de hábitos y comportamientos animales que se pueden comparar con la conducta humana. Al contrario, la imitación del hombre por el animal a menudo lleva a éste a la perdición, como podemos ver, por ejemplo, en algunas historietas en las que la atracción por la música, típica manifestación de la cultura humana, hace que un animal sea capturado ${ }^{15}$.

\section{PRESENTACIÓN DE LOS PASAJES OBJETO DE ANÁLISIS}

Ateneo y Eliano tocan en ocasiones los mismos tópicos y tienen algunas fuentes en común. Pero, además, el Banquete de los eruditos fue leído directamente por Eliano ${ }^{16}$, quien, sin reconocer jamás su deuda, utiliza en más de una ocasión material sacado de dicha obra, como creo que se hará patente a lo largo de este artículo. El análisis

${ }^{14}$ Resulta interesante sobre este tema la contribución de Vespa, 2013-2014.

${ }^{15}$ Véanse, por ejemplo, $H A$ I 39, VI 31 y 32, XII 43, etc.

${ }^{16}$ Se piensa actualmente (véase Rodríguez-Noriega, 1998: 10) que el Banquete de los eruditos pudo ser compuesto entre el 192 y el 195 d.C., cuando Eliano tendría algo más de veinte años. La deuda directa de Eliano con el Banquete de los eruditos ya fue señalada por Wilson, 1997: 10-11. 
de algunos de los pasajes en los que Eliano bebe de Ateneo servirá para poner de manifiesto las diferentes actitudes ante las fuentes del uno y el otro, permitiéndonos conocer un poco mejor sus métodos y personalidad como autores, y valorar su frabilidad como transmisores de fragmentos de obras perdidas.

Como veremos en los textos que vamos a comparar, tanto Ateneo como Eliano muestran gran interés por los animales, pero por motivos diferentes. Puesto que ambos comparten la típica vocación erudita de su época, para ellos "científico" significa "científico-anticuario». Esto es lo que explica que Eliano se haya servido ocasionalmente del Banquete de los eruditos como fuente de información para ese ámbito. Pero, aparte de eso, las diferencias entre ambos son patentes. Por ejemplo, si Ateneo ha llevado a cabo un enorme esfuerzo para reunir todo tipo de información sobre diversos animales es porque éstos forman parte del menú servido a los invitados durante el banquete del que trata su obra. De este modo, cada nuevo plato de carne o pescado lleva a los personajes o al narrador a hablar en profundidad sobre el animal en cuestión, aportando datos científicos, literarios y gramaticales, sin olvidar, por supuesto, los referentes a sus cualidades culinarias. Eliano, en cambio, normalmente evita hablar de los animales como comida ${ }^{17}$ y busca en relación con ellos temas susceptibles de convertirse en historias breves, que puedan transmitir alguna enseñanza o moral, y que sean, a la vez, entretenidas (ya dramáticas, ya con tintes cómicos). El deseo de instruir al lector, junto con el componente edificante, está siempre presente en Eliano, incluso cuando la selección del tema viene motivada por el interés de la propia historia en sí.

Pues bien, del texto del Banquete de los eruditos entre IX 387 F y 395 A Eliano extrajo material para tres capítulos consecutivos (27, 28 y 29) del libro Xv de la $H A$, así como para los capítulos 14 y 15 del libro I de las $V H$. En las dos obras de Eliano, el material se presenta en el mismo orden relativo que en Ateneo, como se puede ver en la siguiente tabla, lo que corrobora la deuda de aquél con el Banquete de los eruditos:

\begin{tabular}{|l|c|c|}
\hline Banquete de los eruditos & $H A$ & VH \\
\hline 388 A-B & XV 27 & \\
\hline 388 C-391 A & & \\
\hline 391 B-C & XV 28 & \\
\hline 391 D-393 B & & \\
\hline 393 C-D & & I 14 \\
\hline 393 E-F & XV 29 & \\
\hline 394 A & & \\
\hline 394 B-395 A & & I 15 \\
\hline
\end{tabular}

${ }^{17}$ Eliano incluso rechaza abiertamente el consumo de algunos que considera especialmente nobles, como el delfín, véase NA XII 6. Todo ello ha llevado a Garcia Valdés, 2003, a estudiar las relaciones del autor con el vegetarianismo. Su conclusión es que Eliano tenía una visión positiva de este tipo de alimentación, aunque ello no significa que él mismo lo practicase (entre otros motivos, porque su cargo sacerdotal probablemente no se lo permitiría). 
Cabe señalar que los quince primeros capítulos del libro I de las $V H$, que versan fundamentalmente sobre animales, se piensa ${ }^{18}$ que están formados por material que Eliano había reunido inicialmente para la $H A$, pero que luego, por el motivo que sea, no había llegado a utilizar para dicha obra.

Lo que hoy sabemos del abundante manejo de fuentes de que hace uso Ateneo nos permite descartar que esos paralelismos se deban a que ambos autores estuvieran siguiendo un mismo modelo común más antiguo ${ }^{19}$ : el pasaje de Ateneo está elaborado a partir de material de origen muy diverso, y el orden en el que lo presenta responde a la propia lógica interna del Banquete de los eruditos, de modo que no tendría sentido fuera de la obra. En el pasaje en cuestión, Ateneo se ocupa de diversas aves que son servidas como parte del menú. Pero, como es habitual en él, varias veces se sale del tema principal para tratar otros secundarios, a los que llega por diversas asociaciones de ideas. Ese continuo cambio de tema y el paso de unos animales a otros que se daba en Ateneo fue lo que permitió a Eliano dejar el material que había seleccionado en el mismo orden relativo que tenía en el Banquete de los eruditos, porque, tal como estaba, sin necesidad de cambio alguno, ya presentaba la variedad que buscaba para sus propias obras.

En lo que sigue, vamos a ir analizando en detalle los textos paralelos apuntados arriba.

\section{ATENEO IX 387 F-388 A / ELIANO, NAXV 27}

En el pasaje del Banquete de los eruditos comprendido entre IX 387 A y 388 A, Ateneo diserta sobre un ave, el francolín (Francolinus francolinus L.), a propósito del cual, con el afán enciclopédico y la minuciosidad de bibliotecario que lo caracterizan, ha reunido gran cantidad de datos y cita numerosas fuentes, en concreto: un verso de la comedia perdida Las cigüeñas de Aristófanes (fr. 448 K.-A.), donde se menciona la carne de francolín como muy sabrosa; una paráfrasis de un pasaje de Alejandro de Mindo (fr. 7 Well.), que contiene una descripción física del animal; una cita literal de una obra muy poco conocida del historiador helenístico Sócrates de Argos, titulada Sobre fronteras, lugares, fuego y piedras ( $F G r H 310$, fr. 17); un verso de Hiponacte, donde de nuevo se menciona el ave como alimento (fr. 37.1 Degani); una alusión a las menciones del francolín en las Aves (vv. 249, 761) y Los acarnienses (v. 87) de Aristófanes; y, finalmente, una digresión gramatical sobre la correcta acentuación y flexión del nombre del ave.

De todo ese material, lo que llamó la atención de Eliano fue, en concreto, la cita de Sócrates de Argos, que contiene una curiosa anécdota sobre el cambio de

\footnotetext{
${ }^{18}$ Véase Wilson, 1997: 6.

${ }^{19}$ Cf. Wilson, 1997: 11.
} 
canto supuestamente experimentado por los francolines en Egipto en tiempos de una gran hambruna; el autor comenta, también, que estas aves dejan de cantar en cautividad, pero recuperan su voz cuando se las libera de nuevo. Ese breve relato, que Ateneo, como hemos apuntado, cita literalmente, ha servido de inspiración a Eliano para construir el capítulo 27 del libro XV de la $H A$, como podemos comprobar al comparar los dos textos, que ofrecemos a continuación en columnas enfrentadas:

Deipnosophistae IX 387 F-388 B

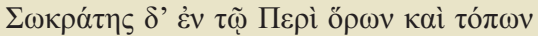

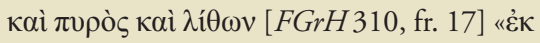

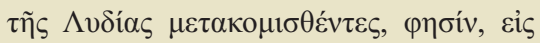

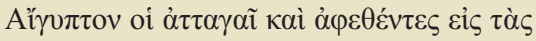

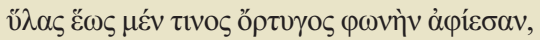

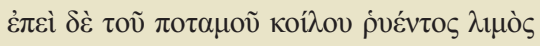

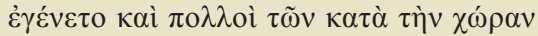

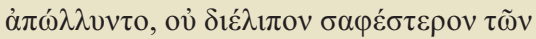

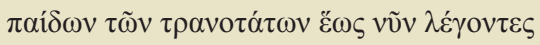

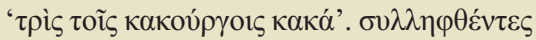

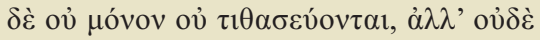

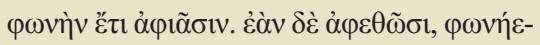

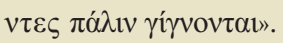

Natura animalium XV 27

$\Lambda$ ó

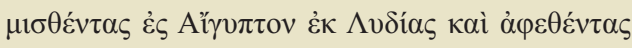

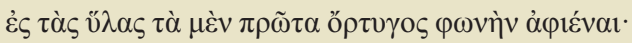

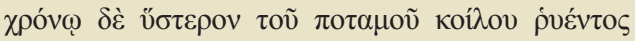

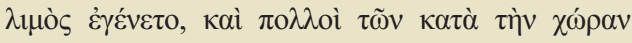

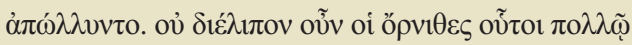

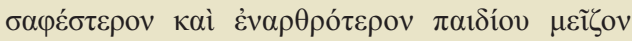

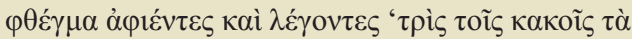

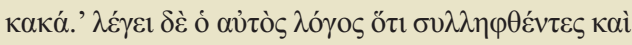

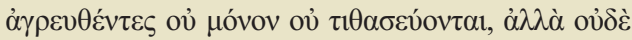

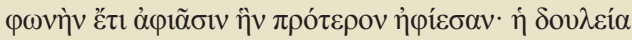

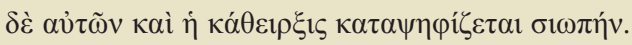

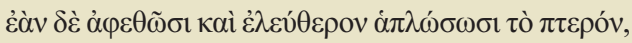

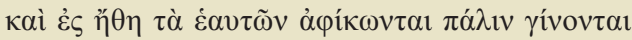

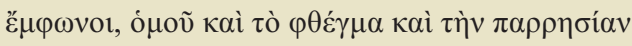
$\alpha \nu \alpha \lambda \alpha \beta \delta^{\prime} \tau \tau \varepsilon \varsigma$.

Resulta evidente que Eliano no estaba interesado en mencionar a Sócrates de Argos como autoridad (no digamos ya a Ateneo), y que su idea cuando tomó el material era darle nueva forma, adaptándolo a su propósito didáctico y moralizante. Así, para empezar, no cita por su nombre a ninguno de los dos autores, sino que

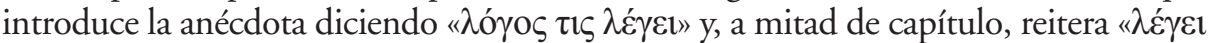

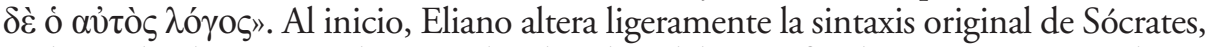
incluyendo algunos cambios en el orden de palabras, a fin de situar en primer lugar la mención del francolín, que es el protagonista de su historia. También añade que el francolín es un ave, información que podría ser necesaria para sus lectores (los del Banquete de los eruditos, en cambio, ya sabían a esas alturas que se estaba hablando de aves, así que Ateneo, a su vez, no había necesitado explicitarlo).

Además de eso, podemos observar cómo, por un lado, Eliano expresa en tres frases breves lo que en Sócrates era una sola, bastante larga, haciendo así que el texto sea de lectura más fácil. Pero, al mismo tiempo, amplifica algunas partes, con el fin de atraer la atención del lector sobre ciertos puntos particulares de la historia. Así, alarga la comparación del canto del ave con el lenguaje infantil, describe lo que dicen

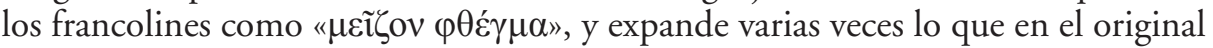
es una única palabra mediante el empleo de una figura retórica denominada «ditología sinonímica». Esta figura, como todos los tipos de pleonasmo, se emplea para 
focalizar la atención y reforzar el concepto expresado mediante ella. Así, Eliano escribe

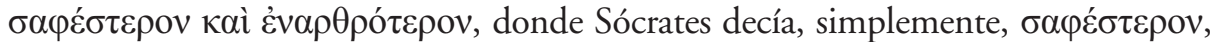

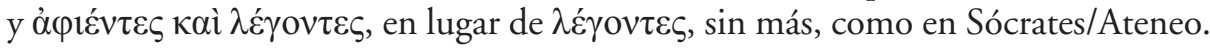
Todo ello para expresar que estos francolines no sólo sabían hablar, sino que, además, lo hacían de una manera muy clara y comprensible. La frase supuestamente pronunciada por las aves, que era una máxima (o se convirtió después en una máxima ${ }^{20}$ ), está expresada de una manera ligeramente diferente en Eliano, que llama a los malhechores

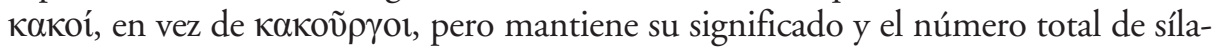

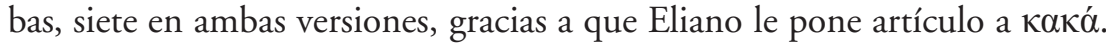

Hasta este punto, como puede apreciarse, lo que se observa es que Eliano tiende fundamentalmente a parafrasear el original, de acuerdo con las prácticas aprendidas en la escuela de retórica. En la segunda parte del capítulo, en cambio, se aparta mucho más de su fuente, porque es aquí donde introduce su personal lectura moral del relato, inspirada por la historia de que los francolines pierden la voz al ser capturados, y no se dejan domesticar ${ }^{21}$, pero recobran su canto al ser liberados. De este modo, lo que en Sócrates de Argos era una mera anécdota expresada con una pocas

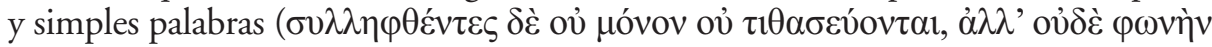

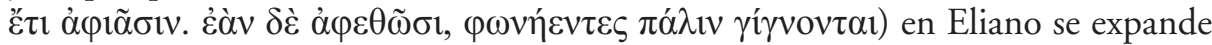
y adquiere un sentido mucho más trascendente. Aquí de nuevo vemos cómo Eliano recurre a la ditología sinonímica, en esta ocasión para enfatizar el momento en el que las aves pierden su libertad, en el que son $\sigma 0 \lambda \lambda \eta \varphi \theta \varepsilon \dot{v} \tau \varepsilon \varsigma \varsigma \alpha \alpha \grave{~} \alpha \gamma \rho \varepsilon v \theta \varepsilon \dot{v} \tau \varepsilon \zeta$, según dice él, en lugar de $\sigma 0 \lambda \lambda \eta \varphi \theta \varepsilon ́ v \tau \varepsilon \varsigma$, sin más, como en su fuente. El momento de la puesta en libertad de las aves también es destacado por Eliano mediante un pleonasmo, de manera que, en lugar de decir simplemente, como en Sócrates/Ateneo غ̇̀̀v $\delta \grave{\varepsilon}$

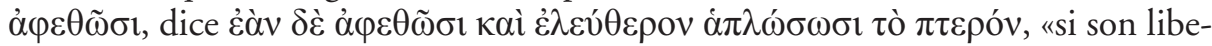
radas y despliegan sus alas con libertad». La sustitución léxica típica de la paráfrasis se observa también, por ejemplo, en la frase $\pi \alpha ́ \lambda ı v ~ \gamma i ́ v o v \tau \alpha \imath ~ \varepsilon ̋ \mu \varphi \omega v o l$, donde en

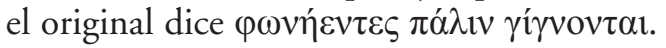

Pero lo que es especialmente destacable es el empleo por parte de Eliano de palabras como $\pi \alpha \rho \rho \eta \sigma i ́ \alpha$, «libertad de palabra», que pertenece a la esfera de la sociedad y la política humanas, pero que aquí se aplica a unos animales. Aún más, el autor

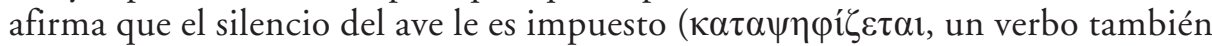
con claras connotaciones políticas) por la esclavitud ( $\delta$ ov $\lambda \varepsilon i ́ \alpha)$ y el confinamiento ( $\kappa \alpha ́ \theta \varepsilon ı \xi \xi \varsigma$ ), sustantivos que también pertenecen a la esfera humana. Cuando hablamos de animales como si fueran personas, lo que hacemos es enfatizar su comportamiento racional, moral o estético ${ }^{22}$. Esta es una estrategia empleada continuamente

${ }^{20}$ Véase CPG II, p. 683.89.

${ }^{21}$ Debemos decir, sin embargo, que los vendedores modernos de estas aves las describen como muy fáciles de criar en cautividad.

${ }^{22}$ Cf. Lakoff - Turner, 1989: 168. 
por Eliano, en consonancia con su filosofía personal, y en este caso sirve para enfatizar los aspectos morales de la contraposición entre la libertad y la prisión o la esclavitud. La idea se refuerza mediante la frase lapidaria con la que el autor cierra el capítulo, que dice que los francolines «recuperan a la vez la voz y la libertad de expresión»

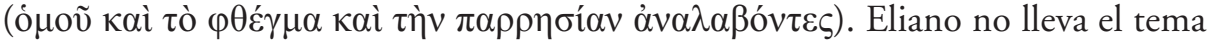
más allá, ni hace ninguna comparación con ninguna situación similar que pueda darse en la esfera humana, pero la idea implícita es clara. El autor quizás no quiso ser más explícito porque los temas de la prisión y la pérdida de la libertad de expresión eran delicados en términos políticos.

\section{ATENEO IX 391 B-C / ELIANO, NA XV 27}

Parece que Eliano no encontró nada adecuado a sus propósitos en el texto de Ateneo entre IX 388 B y 391 A, pero sí que le interesó de nuevo el pasaje sobre el autillo (Otus scops L.) que se extiende entre IX $391 \mathrm{~B}-\mathrm{C}$, del que tomó el material para el siguiente capítulo de la $H A$ (es decir, el 28 del libro XV). En el Banquete de los eruditos la mención del ave es incidental, puesto que, en realidad, Ateneo en ese pasaje está hablando de la avutarda (Otis tarda L.), cuyo nombre en griego, ảtí́, es parecido al de un búho de mediano tamaño con unos penachos faciales similares

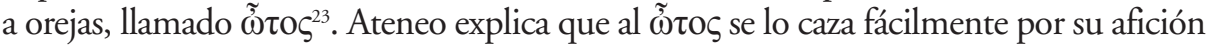
a la mímica, a base de hacerlo imitar a unas personas que se ponen a bailar en frente de él. Esto lleva al autor, por asociación de ideas, a hablar de otro tipo de ave similar,

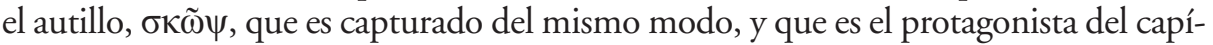
tulo de Eliano. Da la impresión, aunque él no lo dice explícitamente, de que lo que en esta ocasión ha atraído a Eliano es la idea de que el pájaro es capturado por imitar lo que hacen los humanos, en lugar de comportarse como un ave, como debería según la ley natural. Los textos de ambos autores son los siguientes:

Deipnosophistae IX 391 A

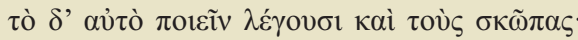

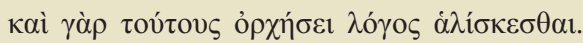

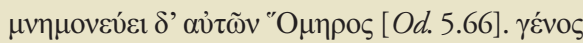

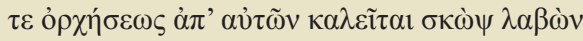

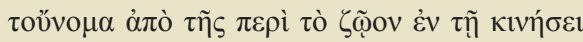

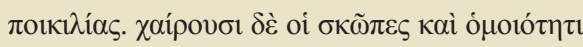

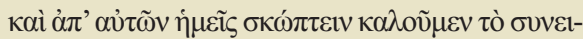

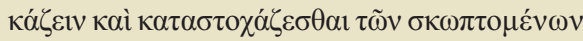

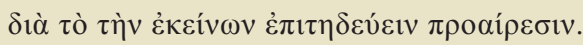

\section{Natura Animalium XV 28}

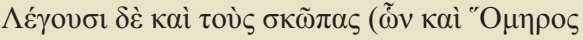

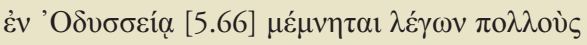

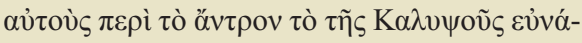

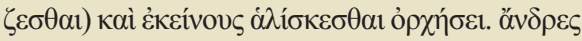

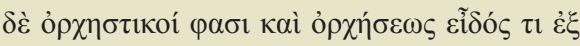

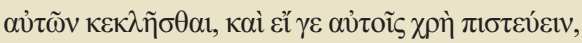

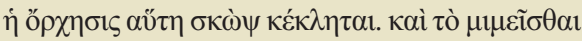

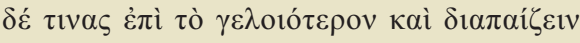

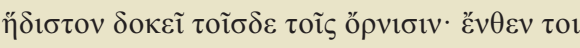

${ }^{23}$ Que podría ser el búho chico (Asio otus L.) o tal vez el búho campestre (Asio flammeus L.). 


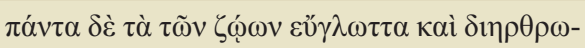

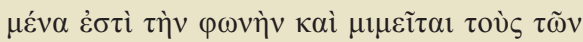

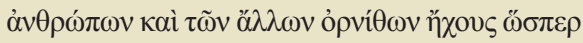

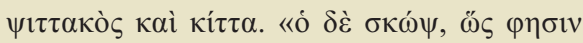

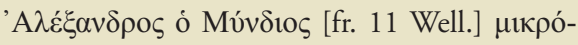

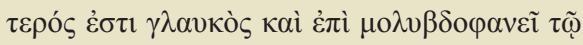

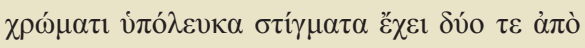

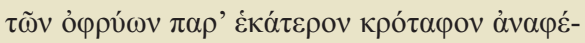

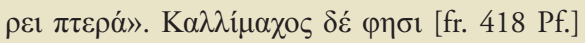

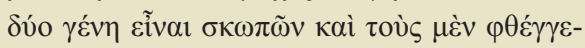

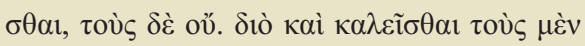

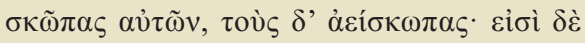

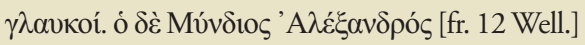

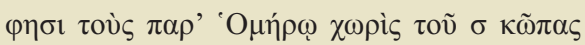

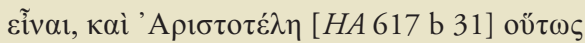

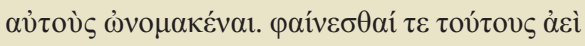

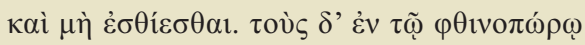

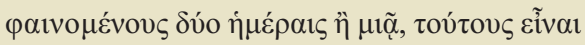

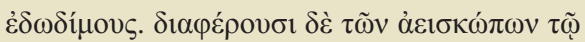

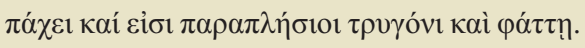

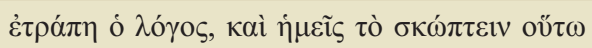

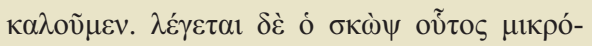

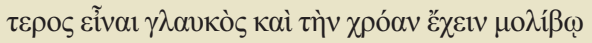

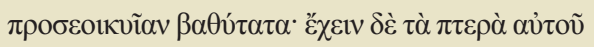

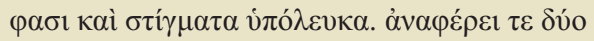

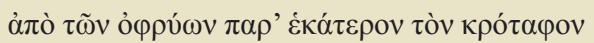

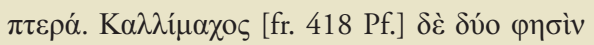

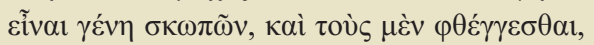

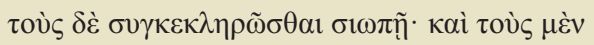

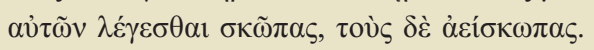

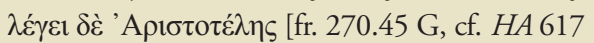

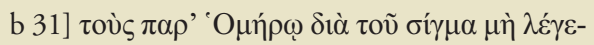

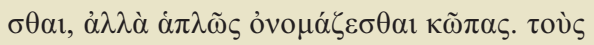

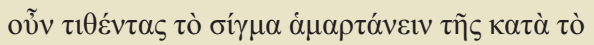

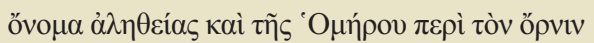

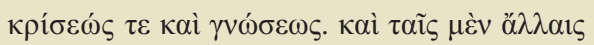

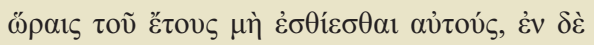

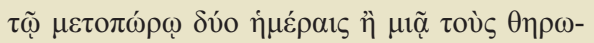

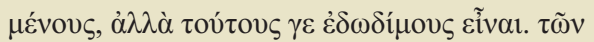

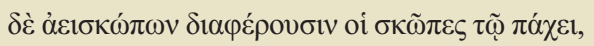

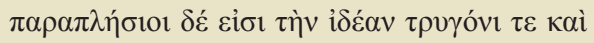

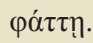

Como se puede apreciar al comparar las dos versiones, la información general que se da en ambos textos no sólo es la misma, sino que, además, aparece en el mismo orden relativo. De hecho, en esta ocasión el capítulo de Eliano no contiene la típica historia breve con un final del que se obtiene alguna moraleja, sino que refleja la acumulación de informaciones independientes que Ateneo había reunido, de acuerdo con sus intereses enciclopédicos de gramático. Eliano únicamente ha prescindido de una digresión en la que, por asociación de ideas, Ateneo hablaba de varias aves capaces de imitar la voz humana, así como de la parte final (que no hemos recogido en el texto), en la que se cita primero a Espeusipo (fr. 26 Tarán) y Epicarmo (fr. 236 R.-N. = fr. $164 \mathrm{~K}$.- A.) como autoridades que certifican el empleo de la palabra $\kappa \tilde{\omega} \pi \varepsilon \zeta$, sin sigma inicial, en lugar de $\sigma \kappa \tilde{\omega} \pi \varepsilon \varsigma$, y, finalmente, a Metrodoro $(F G r H 184$, fr. 3) como otra fuente adicional que asegura que los autillos son capturados cuando imitan a gente que baila frente a ellos.

Por lo demás, se aprecia de nuevo que Eliano tiende a la paráfrasis, algunas veces, alterando, simplemente, el orden de palabras original; otras, recurriendo a sinónimos o expresiones que le permiten decir lo mismo, pero de manera diferente; $y$ otras, haciendo algunas adiciones personales, buscando mejorar el texto original. Así, por ejemplo, expande la información sobre la aparición de los autillos en la Odisea, mencionando su presencia junto a la caverna de Calipso, y más adelante añade un comentario

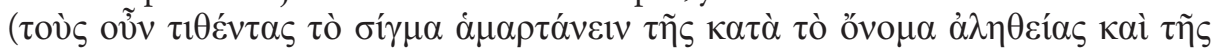




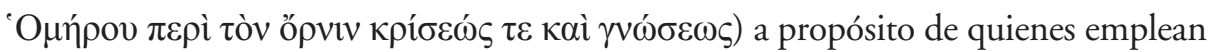
la palabra con sigma en Homero.

Pero también podemos observar que los dos $\kappa \alpha i$ de la frase que abre el capítulo

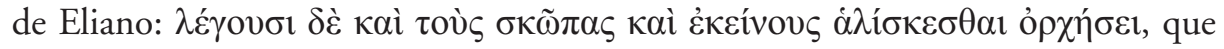
no tienen justificación alguna en relación con lo que acaba de decirse en el capí-

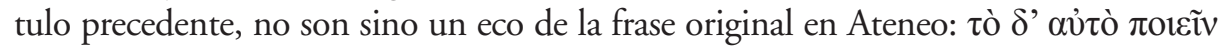

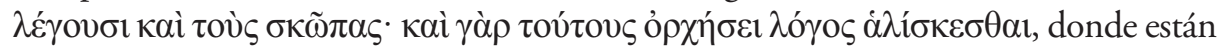
plenamente justificados, porque Ateneo está diciendo que los autillos son también capturados del mismo modo que los $\omega ் \tau i ́ \delta \varepsilon c$. Es decir, se trata de un elemento procedente de su fuente, que Eliano no pulió del todo al redactar la frase, y contribuye a poner en evidencia su dependencia del texto de Ateneo.

Vemos así mismo que Eliano únicamente cita sus fuentes en la medida en que le son útiles, en este caso, como autoridad. Así, en lugar de mencionar a Ateneo, recurre a expresiones como $\lambda \dot{\varepsilon} \gamma \sigma v \sigma l, \varphi \alpha \sigma \iota$ o $\lambda \varepsilon ́ \gamma \varepsilon \tau \alpha l$, y atribuye la información sobre

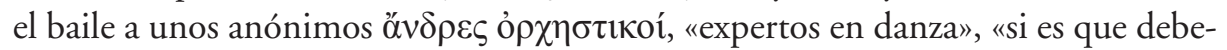
mos confiar en ellos», poniendo en condicional la información que transmite. Pero tampoco nombra a Alejandro de Mindo, del que en este caso procede no sólo la descripción física del autillo, sino también toda la parte final de su capítulo, después de la mención de Calímaco, como establece claramente Ateneo (que en esta ocasión cita a Aristóteles indirectamente, a través de Alejandro). Eliano, sin embargo, presenta toda esa información como si procediera de Aristóteles, cuando en realidad sólo una parte de la misma está tomada de él, como podemos comprobar acudien-

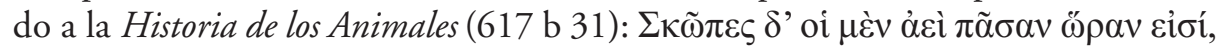

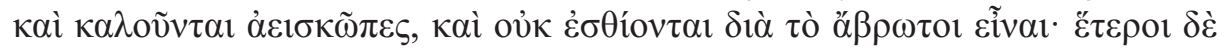

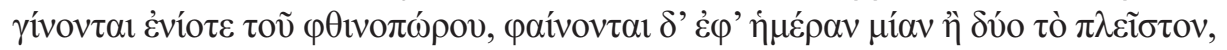

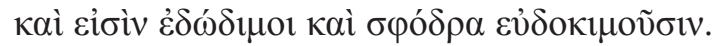

Este pasaje es también muy interesante porque muestra cómo varios cambios sucesivos en la redacción de un texto pueden llegar a oscurecer su sentido original.

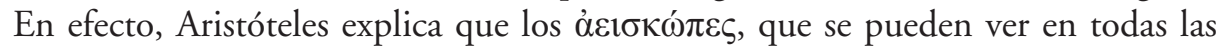
estaciones del año, no se comen, mientras que los $\sigma \kappa \omega ́ \pi \varepsilon \zeta$ a secas, que sólo son visibles unos días al año, son comestibles. En la versión de Ateneo, pasada por el intermedio de Alejandro de Mindo, esta idea ya no está muy claramente expresada, aunque todavía puede deducirse si se lee con atención. Pero ya no sucede lo mismo con el texto de Eliano, que da la sensación de estar hablando únicamente de los $\sigma \kappa \omega ́ \pi \varepsilon \zeta$, con lo que su información resulta muy confusa. Todo esto corrobora, una vez más, que Eliano no conocía directamente el pasaje original de la Historia de los animales de Aristóteles, y dependía sólo de Ateneo (quien, a su vez, seguía a Alejandro de Mindo, del que tomaba de segunda mano la cita de Aristóteles). Comparando las paráfrasis de Ateneo/Alejandro y Eliano con el texto original de Aristóteles, cabe destacar cómo Ateneo conserva en su texto el término empleado por el filósofo para nombrar la época del año $(\varphi \theta$ vvo $\pi \omega ́ \rho \circ v)$ en que son comestibles los $\sigma \kappa \omega ́ \pi \varepsilon \zeta$, mientras que

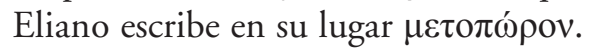




\section{ATENEO IX 393 C-F / ELIANO, VH I 14 - HA XV 28}

Un poco más adelante en su obra, en IX 393 C-F, Ateneo habla de un ave que, según dice, les era servida con frecuencia a él y sus amigos durante los banquetes: el cisne. Como es normal en él, Ateneo de nuevo ha reunido mucha información sobre el animal, y menciona cuidadosamente todas sus fuentes, que en este caso son Aristóteles (fr. 344 R. = 262 G.); Alejandro de Mindo (fr. 17 Well.); un escrito de Hegesianacte de Alejandría titulado La historia de Troya de Cefalión ( $F G r H 45$, fr. 7); y otra obra que llevaba por título Origen de las aves, que Ateneo cita de segunda mano, siguiendo al historiador Filócoro $(F G r H 328$, fr. 214). El Origen de las aves es un poema épico atribuido a una poetisa helenística llamada $\mathrm{Beo}^{24}$, cuyo tema eran, al parecer, las metamorfosis de personas en aves. La historia de que, según Beo, el héroe Cicno, transformado en ave, había tenido amores con una garza, sirve en Ateneo de transición para contar la historia de Gérana y el origen de la enemistad entre las garzas y los pigmeos.

Pues bien, todo apunta a que inicialmente Eliano, al hilo de su lectura del Banquete de los eruditos, había recogido en sus notas buena parte del material reunido por Ateneo para toda esta sección: pero, finalmente, seleccionó para la $H A$ sólo la historia de Gérana y los pigmeos, de la que trata en XV 29. Tiempo más tarde, sin embargo, volvió sobre sus antiguas notas, y empleó la parte inicial, anteriormente descartada, para elaborar el capítulo XIV del libro I de las $V H$. Ofrecemos a continuación los textos de Ateneo y Eliano de nuevo en columnas enfrentadas.

\begin{tabular}{|c|c|}
\hline Deipnosophistae IX 393 C-F & Varia historia I 14 \\
\hline 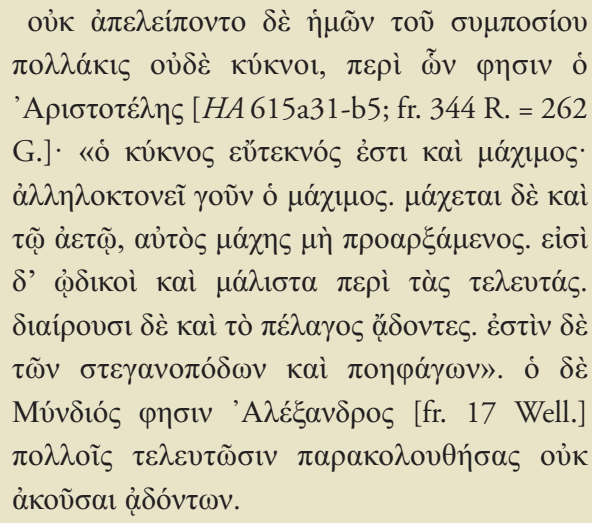 & 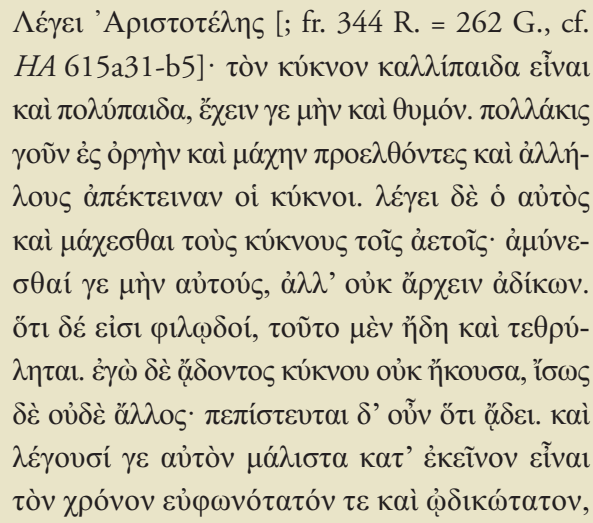 \\
\hline
\end{tabular}

${ }^{24}$ Aunque Ateneo vacila sobre si se trataba de una poetisa o más bien de un poeta. 


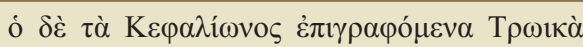

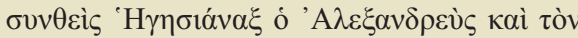

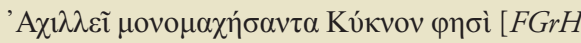

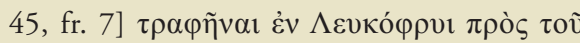

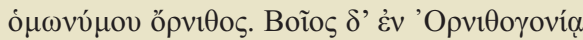
ทे Boı́,

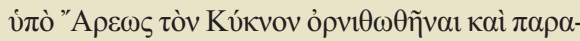

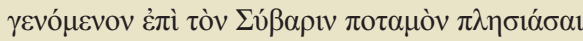

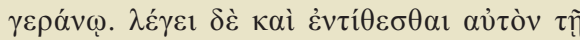

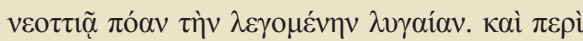

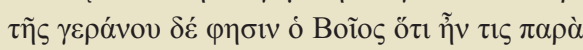

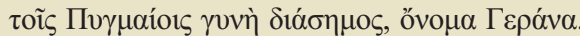

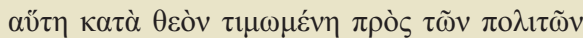

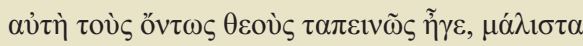

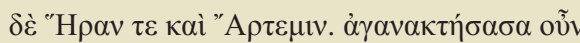

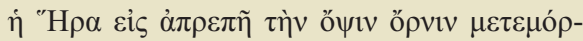

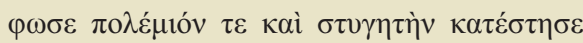

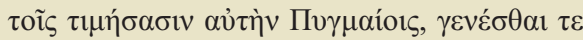

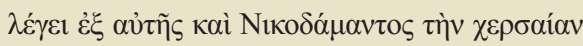

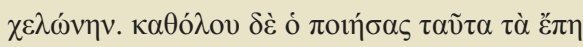

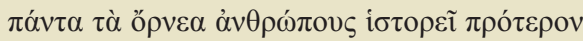

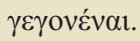

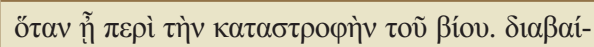

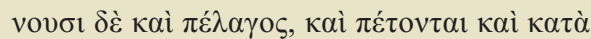

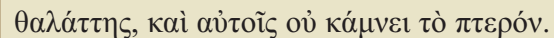

\section{Natura animalium XV 29}

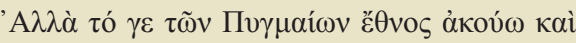

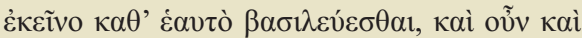

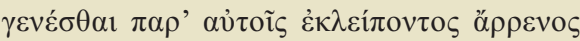

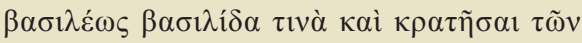

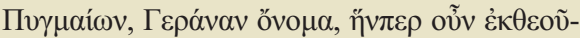

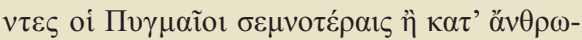

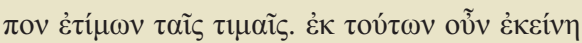

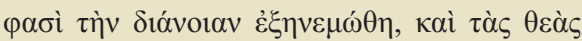

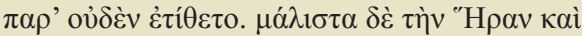

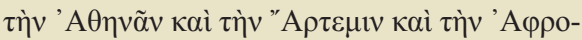

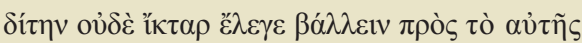

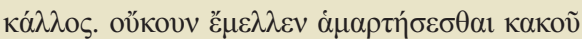

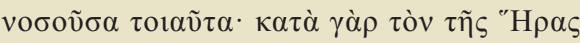

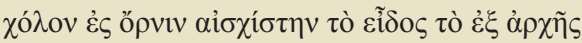

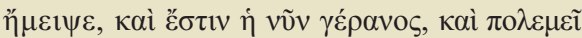

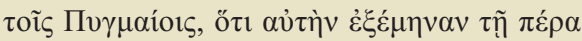

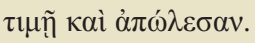

Siguiendo el orden del Banquete de los eruditos, vamos a ocuparnos en primer lugar del capítulo 14 del libro I de la VA de Eliano. La comparación entre los dos pasajes pone de manifiesto cómo de nuevo éste ha seleccionado sólo una parte de los datos eruditos reunidos por Ateneo. Para empezar, no menciona que los cisnes sean comestibles, que es justamente la nota que abre la sección en Ateneo; ya hemos tenido ocasión de comentar cómo en la $H A$ Eliano evita normalmente hablar de los animales como alimento. Está claro que para un autor que muchas veces presenta las costumbres y el comportamiento animal como un modelo para aquellas personas que no actúan conforme a la Naturaleza, poner de manifiesto el empleo de los animales como alimento sería incongruente, o incluso contrario a sus propósitos edificantes.

Por otro lado, podemos observar que la única autoridad de las mencionadas por Ateneo que también cita explícitamente Eliano es, nuevamente, Aristóteles. El resto del contenido del capítulo, sin embargo, es exactamente el mismo que leemos en Ateneo, pero expresado con diferentes palabras, de acuerdo, una vez más, con la práctica de la paráfrasis. De este modo, Eliano sustituye las expresiones originales por sinónimos, al tiempo que algunas veces amplía el texto con contribuciones personales. Así, por ejemplo, donde Ateneo, citando a Aristóteles, dice que el cisne es $\varepsilon v ̋ \tau \varepsilon \kappa v o \varsigma$, que puede significar tanto «que tiene buenos o hermosos hijos» como 


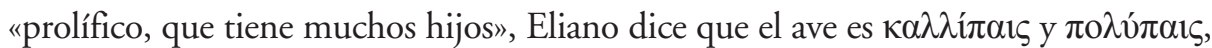
haciendo explícitos los dos posibles significados del adjetivo, como glosándolo. También elabora algo más el tema de la agresividad de los cisnes (uno de sus tópicos favoritos), y añade un toque moralizante (también típicamente suyo) cuando, al decir que, en sus luchas contra las águilas, los cisnes no son los primeros en atacar, emplea

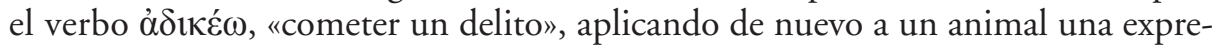
sión típica de la esfera humana. En cambio, la cita de Aristóteles aducida por Ateneo simplemente dice que el cisne no es el que empieza la pelea, como corrobora el propio texto de Aristóteles, HA 615a31-b5:

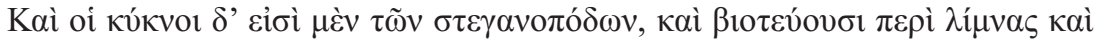

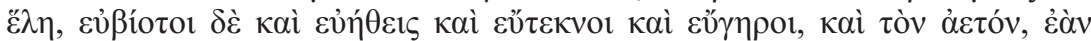

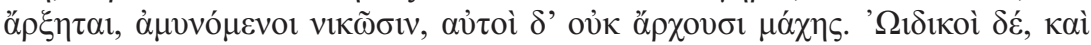

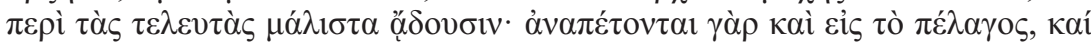

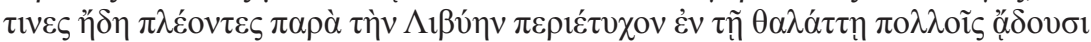

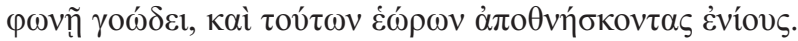

Eliano también se detiene más que Ateneo en la idea de que el cisne vuela cruzando el mar, información que, además, cambia de lugar en su texto, dejándola para el final del capítulo. Pero donde la manipulación del material original es más llamativa es en la parte donde, hablando sobre el canto del cisne (otro punto que elabora más que su fuente), Eliano afirma que él personalmente nunca ha oído a un cisne cantar, y que quizás tampoco lo ha hecho ninguna otra persona ( $\dot{\varepsilon} \gamma \omega \grave{\delta} \delta \dot{\varepsilon}$ ợ $\delta o v \tau o \zeta$

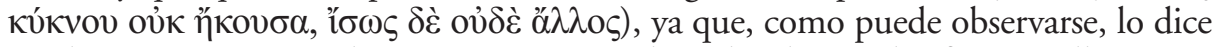
en el mismo punto en el que Ateneo cita a Alejandro de Mindo (fr. 17 Well.), quien afirmaba que, pese a haber observado muchas veces cisnes en el trance de muerte,

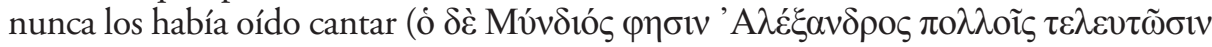

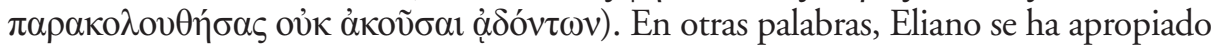
de la idea, presentándola como si fuera algo que se le hubiera ocurrido a él personalmente, y ocultando por completo el testimonio de Alejandro.

De la segunda parte del pasaje de Ateneo, Eliano ha seleccionado específicamente la historia mítica de Gérana y los pigmeos, que, como ya hemos indicado, es el tema del capítulo 29 del libro XV de la $H A$. En esta ocasión Eliano da al relato un toque muy personal, con importantes cambios y adiciones, tal vez en parte inspiradas en otras fuentes distintas de Ateneo. De este modo, aunque introduce la historia con un àkov́ $\omega$, «oigo decir», lo que hace más bien es crear una versión original, de nuevo resaltando las consecuencias morales de la historia que le sirve de inspiración. Empieza explicando que los pigmeos tenían su propio sistema de gobierno y que, al faltarles el rey, en una ocasión fueron gobernados por una reina llamada Gérana. Esta es la primera diferencia importante con respecto a Ateneo, que se refiere a Gérana solo como una mujer importante y muy honrada por sus compatriotas. Que esto era, en efecto, lo que decía Beo en su poema lo confirman otras dos fuentes. Una es Antonino Liberal (XVI 1), que resume el pasaje del poema de Beo, del siguiente modo:

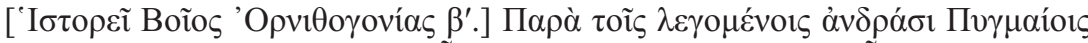

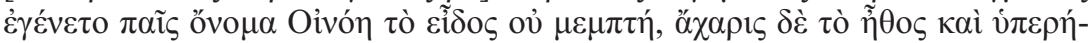

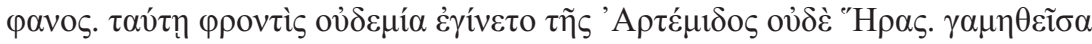




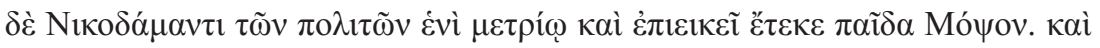

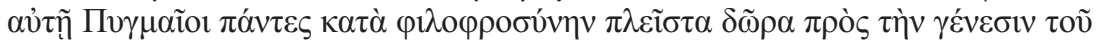

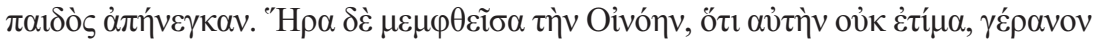

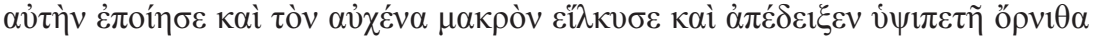

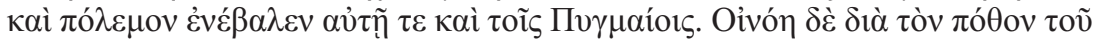

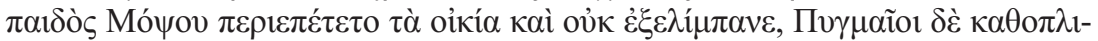

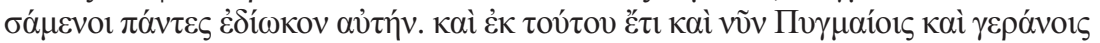

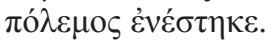

La otra es Ovidio, que menciona la historia de pasada en las Metamorfosis VI 90-93:

altera Pygmaeae fatum miserabile matris

pars habet: hanc Iuno victam certamine iussit

esse gruem populisque suis indicere bellum.

Como puede apreciarse, ninguno de ellos dice tampoco que la protagonista fuera una reina, y Antonino, además, explícitamente indica que estaba casada con un ciudadano de bien, llamado Nicodamas, y que tenían un hijo llamado Mopso. Nicodamas también es mencionado por Ateneo, que dice que él y Gérana fueron los padres de la tortuga de tierra, de modo que ese era posiblemente el final de Mopso en el poema de Beo. Ovidio también se refiere a Gérana como una «madre pigmea». Aparte de eso, mientras Ateneo dice que Gérana era honrada "como si fuera una diosa», Eliano va más allá y asegura que los pigmeos la habían deificado, y que los honores que le rendían eran demasiado augustos para un ser humano. En Antonino Liberal no figura nada de eso, limitándose el autor a decir que los pigmeos le ofrecieron a la heroína muchos regalos con ocasión del nacimiento de su hijo.

El clímax de la historia también es convenientemente alargado por Eliano. Mientras que Ateneo comenta, mediante una frase muy corta, que Gérana no sentía mucho respeto hacia las auténticas diosas, especialmente Hera y Ártemis, Eliano se extiende más en el tema, y añade el motivo de la rivalidad en belleza, que tal vez le haya podido ser sugerido por Ovidio, que dice que la pigmea fue vencida por Juno en un certamen de algún tipo, sin especificar más. Pudiera ser que Eliano (u otra fuente conocida por él de la que no ha quedado noticia) se inspirase en el mito de la manzana de la discordia, lo que podría explicar la adición de Atenea y Afrodita a la lista de diosas ofendidas, ninguna de las cuales es mencionada ni por Antonino (que, como Ateneo, sólo habla de Hera y Ártemis), ni por Ovidio, que sólo menciona a Juno.

Cabe destacar que Eliano utiliza aquí varias expresiones coloquiales para dar

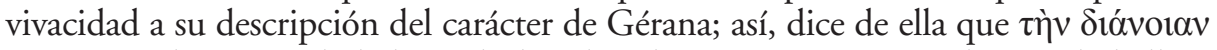

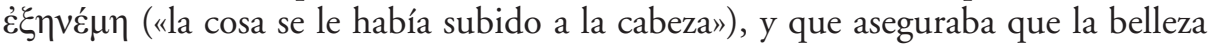

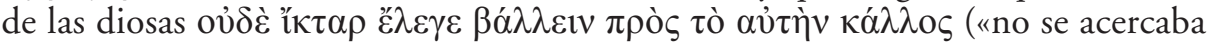
a la suya ni de lejos»). De este modo, Eliano focaliza la impiedad de Gérana en el motivo de la vanidad femenina, completamente ausente en los otros autores conocidos que transmiten la historia. De hecho, la insistencia de Antonino en el tema del hijo hace sospechar que en el poema de Beo la rivalidad con Hera pudo tener algo que ver con el orgullo de Gérana por Mopso (que, como hemos señalado, finalmente fue metamorfoseado en tortuga terrestre). 
La metamorfosis de Gérana es relatada por Eliano en términos similares a los empleados por Ateneo, aunque en lugar de describir el nuevo aspecto de Gérana

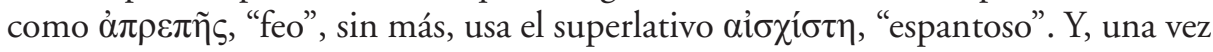
más, pone fin a la historia insistiendo en sus aspectos moralizantes.

\section{ATENEO IX 394 B-395 A / ELIANO, VH I 15}

Terminada la sección sobre el cisne, Ateneo pasa a ocuparse de las tórtolas y las palomas, en un pasaje del que es patentemente deudor Eliano en $V H$ I 15, como se observa al comparar los dos textos, que ofrecemos de nuevo en columnas enfrentadas.

Ath. IX 394 B-395 A

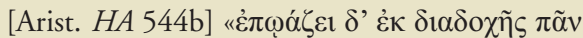

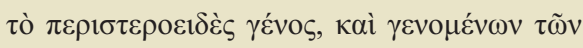

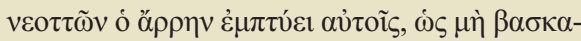

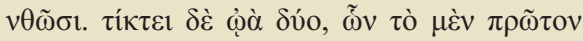

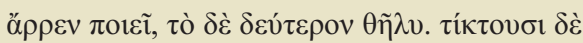

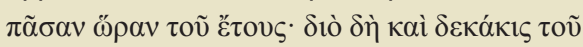

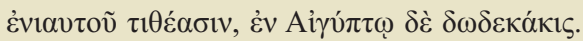

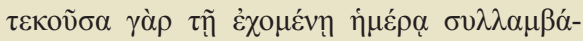

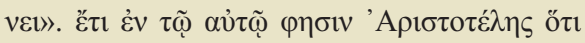

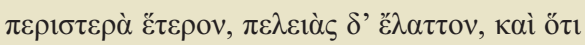

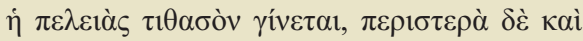

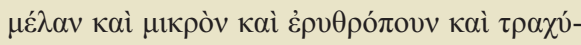

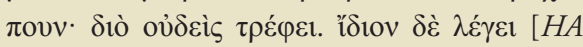

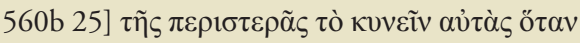

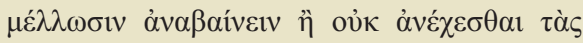
$\theta \eta \lambda \varepsilon i ́ \alpha \varsigma$ ò $\delta \varepsilon \dot{\varepsilon} \pi \rho \varepsilon \sigma \beta v ́ \tau \varepsilon \rho \circ$, ,

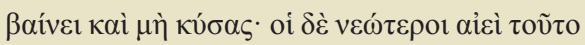

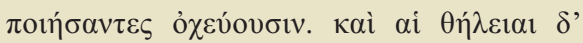

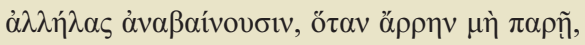

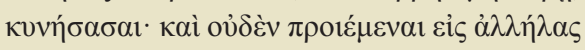

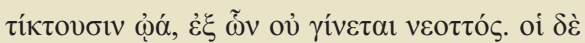

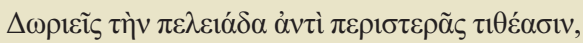

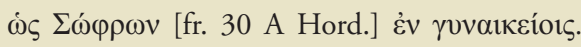

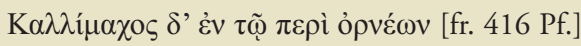

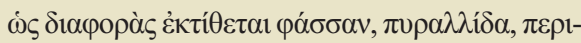

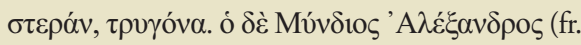

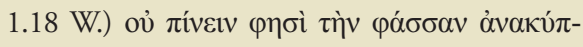

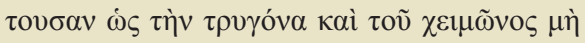

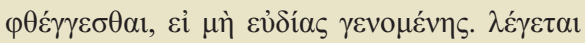

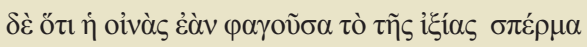

VH I 15

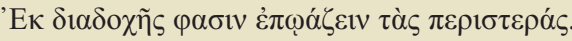

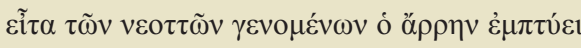

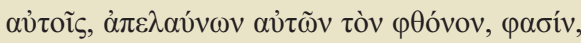

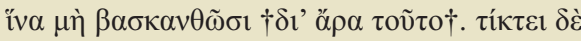

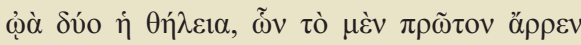

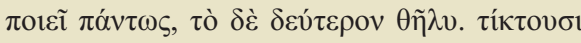

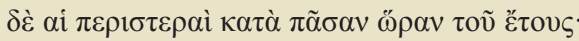

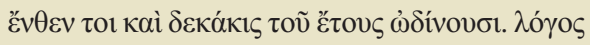

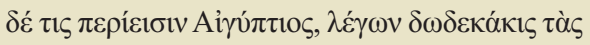

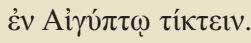

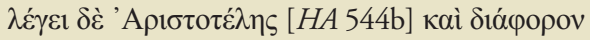

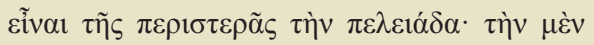

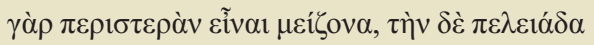

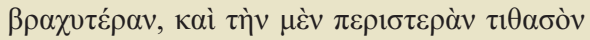

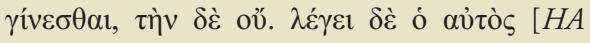

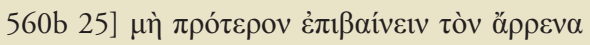

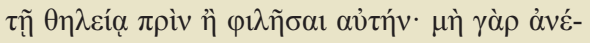

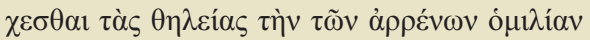

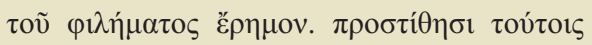

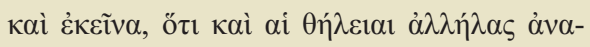

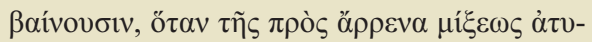

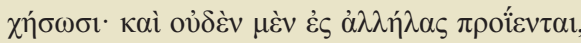

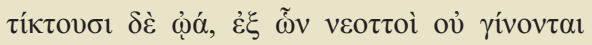

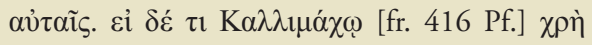

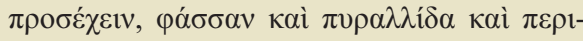

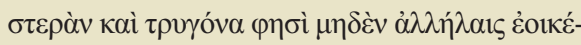

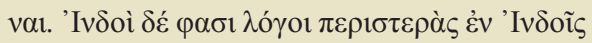

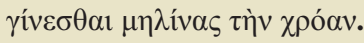

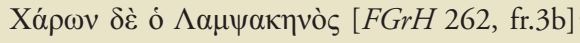

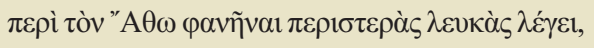




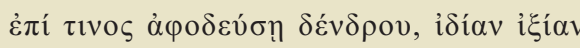

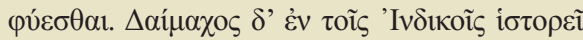

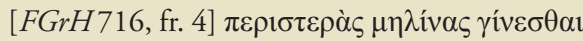

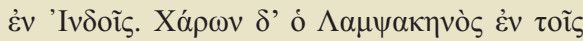

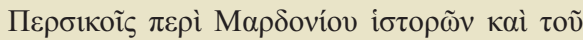

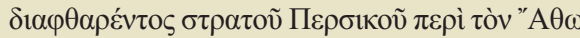

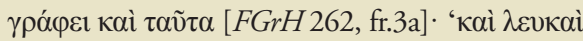

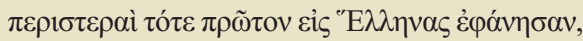

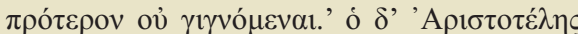

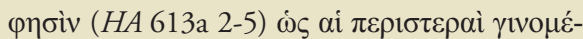

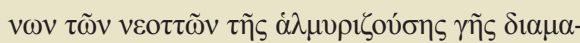

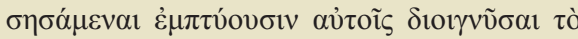

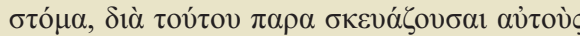

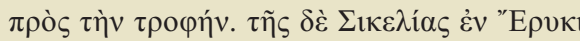

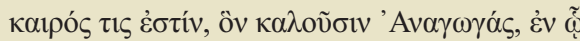


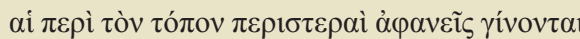

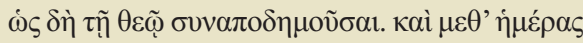

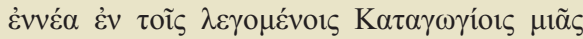

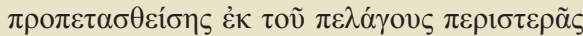

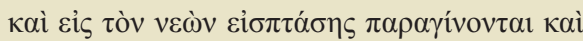

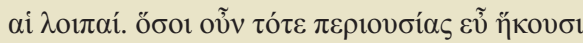

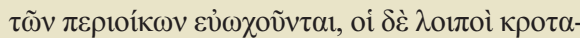

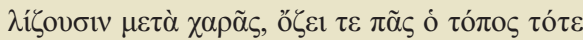

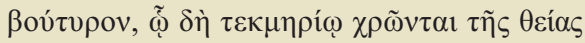

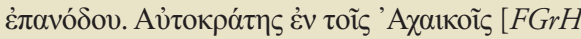

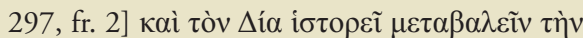

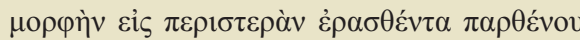

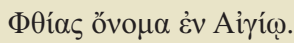

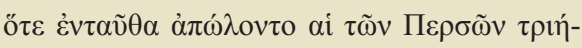

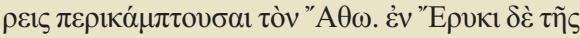

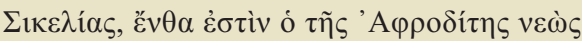

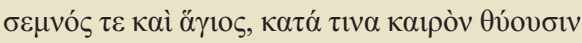

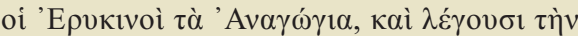
'А

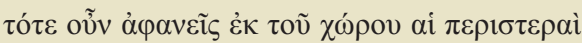

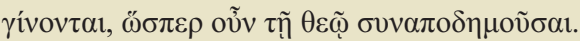

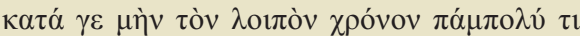

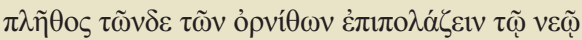
$\tau \tilde{\Upsilon} \varsigma \theta \varepsilon \circ \tilde{\omega} \dot{\omega} \mu \lambda \hat{\gamma} \gamma \eta \tau \alpha 1$.

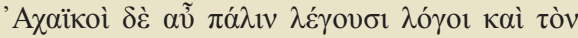

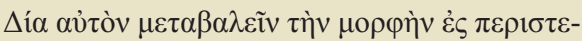

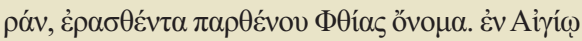

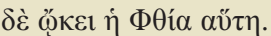

En este caso, como puede apreciarse, el material de Ateneo ha sido muy poco elaborado por Eliano, aunque sí se observa que el original es sometido continuamente a paráfrasis, buscando decir lo mismo de otra manera. Por ejemplo, si comparamos el primer párrafo de ambos textos, vemos que Eliano, aparte de que evita

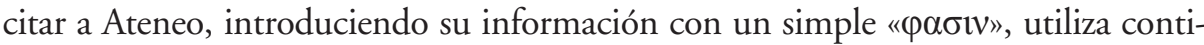

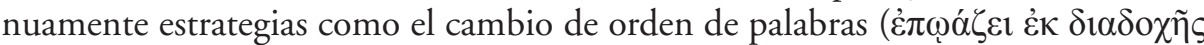

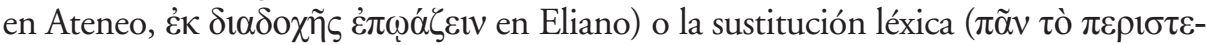

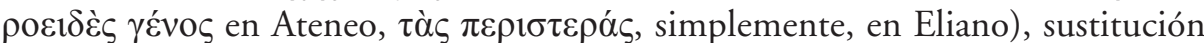

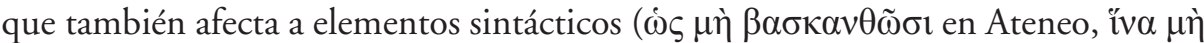
$\beta \alpha \sigma \kappa \alpha v \theta \tilde{\omega} \sigma \mathrm{e}$ en Eliano), y lo mismo se observa a lo largo de todo el capítulo. Eliano, además, prescinde de parte de la información de Ateneo (la referencia gramatical al nombre dorio de la paloma, ejemplificado por Sofrón, fr. 30 A Hord., y las citas de Alejandro de Mindo, fr. 1.18 W., y Daímaco, FGrH716, fr. 4, hacia la mitad 
del texto, y Autócrates $F G r H 297$, fr. 2, al final), mencionando como autoridades únicamente a Aristóteles, Calímaco y Caronte de Lámpsaco. La referencia a Calímaco pone de manifiesto otra estrategia empleada con frecuencia por Eliano cuando cita sus fuentes, consistente en poner en condicional las afirmaciones de éstas, no haciéndose responsable de su contenido. Así, mientras que Ateneo se limita a citar a Calímaco sin añadir ninguna apreciación, Eliano (que además prescinde de dar

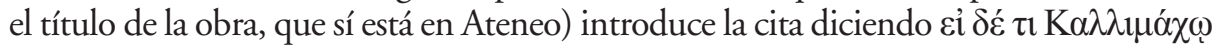

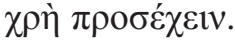

\section{CONCLUSIÓN}

En contraste con Ateneo, que muestra un interés obsesivo de gramático por citar sus fuentes, sólo unos pocos autores (como, por ejemplo, en los casos que hemos analizado, Aristóteles) son tratados por Eliano como autoridades cuyo prestigio refuerza la veracidad de lo que dice, y que, por tanto, merecen ser citadas nominalmente. Sin embargo, hemos comprobado que la mención de una fuente por su parte no garantiza en absoluto que la conozca de primera mano. Así, aparte de que en todos los casos analizados en este artículo creemos que resulta claro que Eliano estaba empleando material extraído de su lectura del Banquete de los eruditos, sin citarlo jamás, hemos visto, por ejemplo, cómo en una ocasión le atribuye a Aristóteles algunas informaciones que en realidad proceden de Alejandro de Mindo, como sí constaba en Ateneo.

Otra clara diferencia entre ambos reside en que mientras que Ateneo tiende a la exactitud en la cita, como se pone de manifiesto allí donde podemos comparar su versión con el texto original citado, Eliano, en cambio, recurre constantemente a los mecanismos de la paráfrasis aprendidos en la práctica escolar, procurando no repetir exactamente lo dicho por sus fuentes, ni siquiera cuando las menciona explícitamente como autoridad. Así, como mínimo tiende a cambiar el orden de palabras y a usar sinónimos y expresiones que le permiten decir lo mismo de otro modo, y muchas veces emplea recursos que le permiten focalizar la atención y reforzar los principales puntos de la historia, desde el pleonasmo a la adición de comentarios personales. También es frecuente en él la estrategia de aplicar al mundo animal vocabulario procedente de la esfera humana, para enfatizar el comportamiento moral de los animales. Todo ello algunas veces lo lleva a elaborar relatos que constituyen paráfrasis más o menos laxas de lo que dice su fuente, pero, otras, da lugar a versiones muy personales de las historias en las que se había inspirado.

En definitiva, a diferencia de Ateneo, que como gramático busca el apoyo del dato exacto aportado por los autores que cita, Eliano no siempre resulta un testimonio fiable si lo que se pretende es la reconstrucción literal del texto de sus fuentes, de las que se aparta en la misma medida en que pone de manifiesto su independencia y originalidad como autor.

\section{REFERENCIAS BIBLIOGRÁFICAS}

Braund, D. (2000): «Learning, Luxury and Empire: Athenaeus' Roman Patron», en D. Braund, J. Wilkins (eds.), Athenaeus and His World, University of Exeter Press, Exeter, pp. 3-22. 
Cribiore, R., $\left(2005^{2}\right)$ : Gymnastics of the Mind. Greek Education in Hellenistic and Roman Egypt, Princeton University Press, Princeton.

García VAldés, M. (2003): "Ciencia y moral: Eliano desde Aristóteles y a la luz del estoicismo y la "zoofilia" moderna", Emerita 70.1: 1-50.

GARCÍA VALDÉS, M. (2013): «La moral en De natura animalium de Eliano: pensamiento estoico y pensa-

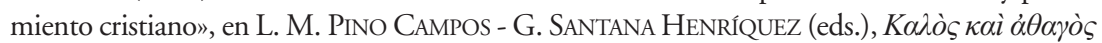
$\dot{\alpha} v \eta \dot{\rho} . \Delta \imath \delta \alpha \sigma \kappa \alpha ́ \lambda o v ~ \Pi \alpha \rho \alpha ́ \delta \varepsilon \imath \gamma \mu \alpha$. Homenaje al profesor Juan Antonio López Férez, Ediciones Clásicas, Madrid, pp. 343-354.

Giangrande, G. (2011): «Sobre el texto y la lengua de Eliano», Veleia 28: 283-290.

JACOB, Ch. (2000): «Athenaeus the Librarian», en D. BRAUND - J. WiLKINS (eds.), Athenaeus and His World, University of Exeter Press, Exeter, pp. 85-110.

JACOB, Ch. (2013): The Web of Athenaeus, Harvard University Press, Cambridge (Mass.).

Lakoff G. - Turner, M. (1989): More than Cool Reason. A Field Guide to Poetic Metaphor, University of Chicago Press, Chicago.

Legras, B. $\left(2004^{3}\right)$ : Éducation et culture dans le monde grec. VII siècle av. J.-C.-IV siècle ap. J.-C., Armand Colin, París.

Marrou, H.-I. (1965'): Histoire de l'éducation dans l'Antiquité, Editions du Seuil, París.

Morgan, T. (20073): Literate Education in the Hellenistic and Roman Worlds, Cambridge University Press, Cambridge.

Roberts, M. (1985): Biblical Epic and Rhetorical Paraphrase in Late Antiquity, Francis Cairns, Liverpool.

RodrígueZ-Noriega Guillén, L. (1998): Ateneo. Banquete de los eruditos. Libros I-III, Gredos, Madrid.

Rodríguez-Noriega Guillén, L. (2000): «Are the Fifteen Books of the Deipnosophistae an Excerpt?», en D. Braund - J. Wilkins (eds.), Athenaeus and His World, University of Exeter Press, Exeter, pp. 244-255.

RodrígueZ-Noriega Guillén, L. (2005): «Aelian and Atticism. Critical Notes on the Text of De Natura Animalium», CQ 55: 455-462.

Rodríguez-Noriega Guillén, L. (2007): «La lengua del De Natura Animalium de Claudio Eliano: apuntes críticos», en A. SÁnCheZ-Ostiz - J. B. Torres Guerra - R. MArTíneZ (eds.), De Grecia a Roma y de Roma a Grecia, un camino de ida y vuelta, Eunsa, Pamplona, pp. 269-282.

RodríGueZ-Noriega Guillén, L. (2011): «Greek and Latin in the late second and early third centuries CE: Atheaneus of Naucratis and Claudius Aelian», en J. B. TORRES GuERrA (ed.), Vtroqve Sermone Nostro. Bilingüismo social y literario en el Imperio Romano. Social and literary bilingualism in the Roman Empire, Eunsa, Pamplona, pp. 81-98.

SCHMid, W. (1893): Der Atticismus in seinen Hauptvertretern von Dionysius von Halikarnass bis auf den zweiten Philostrat, vol. III, W. Kohlhammer, Stuttgart [reimpr. Hildesheim, 1964].

Vespa, M. (2013/14): «Animali maestri: Un sondaggio zooantropologico sul De Natura Animalium di Claudio Eliano", I quaderni del Ramo d'Oro on-line 6: 130-160.

Vessella, C. (2018): Sophisticated Speakers. Atticists Pronunciation in the Atticist Lexica, De Gruyter, Berlín-Boston.

Whitmarsh, T. (2001): Greek Literature and the Roman Empire. The Politics of Imitation, Oxford University Press, Oxford.

Whitmarsh, T. (2005): The Second Sophistic, Oxford University Press, Oxford. 
Wilson, N. G. (1997): Aelian. Historical Miscellany, Harvard University Press, Cambrige (Mass.).

WolfF, C. (2015) : L'éducation dans le monde romain. Du début de la République à la mort de Commode, Roma Aeterna, París. 
